\title{
Characterization of Thermally Cycled Alumina Scales
}

\author{
B. A. Pint, K. L. More, I. G. Wright and P. F. Tortorelli \\ Oak Ridge National Laboratory \\ Oak Ridge, TN 37831-6156
}

\begin{abstract}
Cross-sectional transmission electron microscopy was used to characterize the alumina scales formed on several Ni-base alumina-formers. The alumina scale microstructure of $\mathrm{Ni}$ 20 at $\% \mathrm{Cr}-19 \mathrm{Al}-0.05 \mathrm{Y}$ after $100,1 \mathrm{~h}$ cycles at $1100^{\circ} \mathrm{C}$ was compared to an isothermally-grown scale. Despite being near the onset of mass loss in cyclic testing, very few defects were noted in either scale microstructure. The more adherent scales that form on Hf-doped NiAl and Ni$49 \mathrm{at} \% \mathrm{Al}-2 \mathrm{Cr}$ were also characterized. With the addition of $\mathrm{Cr}$, the formation of $\alpha-\mathrm{Cr}$ precipitates at the metal-oxide interface coincided with increased long-term scale spallation. No similar precipitation mechanism was observed to be associated with scale spallation on NiCrAlY.
\end{abstract}

\section{Introduction}

Though not well recognized, the resistance to scale spallation of NiCrAlY-type alloys is decidedly inferior to reactive element (RE) doped $\beta$-NiAl or FeCrAlY at $1100-1200^{\circ} \mathrm{C}[1]$. This fact, which has significant implications for the metallic bond coats used in thermal barrier coatings on Ni-base superalloys, is often not appreciated because the oxidation behavior of NiCrAlYs is usually evaluated at lower temperatures. Poor alumina scale adhesion leads to loss of the low thermal conductivity ceramic top coat layer[2]. One possible reason for the increased scale spallation on NiCrAlYs may simply be their higher coefficients of thermal expansion compared to $\beta$-NiAl or FeCrAlY[3-5]. However, Ni-base single-crystal superalloys have similar thermal expansion coefficients but have significantly better alumina scale adhesion without any coating[1]. This suggests that other factors may be leading to premature spallation on NiCrAlYs.

In order to investigate a possible scale microstructure-based mechanism for the poor 
spallation resistance of NiCrAlYs, a direct comparison was made between isothermally and cyclically oxidized specimens exposed for the same time and temperature. Oxidation conditions were chosen so that the exposure was terminated prior to the onset of general macroscopic scale spallation (evidenced visually and by net mass losses). This strategy assumes that some type of damage in the scales will be initiated by thermal cycling but not in a similar isothermal exposure. Microscopy results for cast NiCrAlY specimens are contrasted with those for an uncoated commercial single crystal Ni-base superalloy (General Electric alloy René N5) and Hf-doped $\beta$ $\mathrm{NiAl}$ with and without a $2 \% \mathrm{Cr}$ addition. The excellent oxidation performance of $\mathrm{NiAl}+\mathrm{Hf}$ can be compromised when $\mathrm{Cr}$ is added to improve its hot corrosion resistance[6-8].

\section{Experimental Procedure}

Alloys were vacuum induction melted and cast in a $16 \mathrm{~mm}$ diameter, water-chilled copper mold. The Ni-20Cr-19Al-0.05Y (all compositions are given in atomic\%) casting was annealed for $4 \mathrm{~h}$ at $1250^{\circ} \mathrm{C}$ and all other cast alloys at $1300^{\circ} \mathrm{C}$. (The René $\mathrm{N} 5$ alloy was given a proprietary heat treatment.) Specific chemical compositions of the alloys are provided elsewhere[1,9], with nominal values provided here (specific values are provided for RE and $\mathrm{S}$ ).

Coupons were polished to a $0.3 \mu \mathrm{m}$ alumina finish and cleaned in acetone and methanol prior to oxidation. Oxidation exposures were performed by rapid insertion into a hot furnace with a dry, flowing $\mathrm{O}_{2}$ environment. Isothermal oxidation kinetics were measured using a Cahn model 1000 microbalance. Thermal cycles were $1 \mathrm{~h}$ at temperature followed by $10 \mathrm{~min}$ cooling. After exposure, characterization involved light microscopy (of $\mathrm{Cu}$-plated cross sections), fieldemission gun (FEG) scanning electron microscopy (SEM) and FEG transmission electron microscopy (TEM). Both electron microscopes were equipped with energy-dispersive $\mathrm{x}$-ray detectors (EDS). As part of TEM specimen preparation by focused ion beam milling, a thin protective tungsten coating is deposited on the surface of the alumina scale[10]. 


\section{Results and Discussion}

\section{$\underline{\mathrm{NiCrAlY}}$}

The time-temperature exposure for examining "pre-spalled" alumina on NiCrAlY was guided by previous work suggesting that temperatures above $1100^{\circ} \mathrm{C}$ result in rapid scale spallation[1]. Based on long-term exposures (Figure 1), a time of 100h was selected. This time was prior to the onset of significant specimen mass losses for Ni-20Cr-19A1-0.05Y (8ppma S), and also correlated with visual observations of scale spallation. After $100 \mathrm{~h}$ isothermal and cyclic exposures, the scales were virtually identical when viewed by light microscopy and SEM. Figure 2 shows images for the cycled specimen. The initial two-phase alloy microstructure was reflected in the Ni-rich transient oxide (Figure 2a), with little or no transient oxide over the Al-rich $\beta$ phase (darker contrast) but more above the $\gamma$ phase (lighter contrast). Alumina formation during the oxidation exposure led to $\beta$ depletion below the scale such that the substrate near the interface is essentially single phase, Figure 2b. Periodically, Y-rich oxides formed by internal oxidation were observed. In cross-section, the alumina scale had the typical columnar structure[11-13], Figure 2c.

The similarities between the $100 \mathrm{~h}$ isothermal and cyclic specimens also were noted by examination of TEM cross-sections. In the thin areas of the specimen, there was no evidence of any damage due to the 100 thermal cycles. Example areas are shown in Figure 3. No cracks were observed in the scale nor was there evidence of any voids, including those associated with healed cracks [14]. The only voids observed were near the gas interface and were associated with the initial, $\mathrm{NiAl}_{2} \mathrm{O}_{4}$ scale, Figure 3a. The interface between $\mathrm{Al}_{2} \mathrm{O}_{3}$ and $\mathrm{NiAl}_{2} \mathrm{O}_{4}$ is often observed to form void[15,16].

The only clear difference between the isothermal and cycled scales was the morphology of the metal-scale interface, Figure 4. The interface of the scale cycled for $100 \mathrm{~h}$ was much rougher and somewhat less faceted than the isothermal interface. In both cases, there were slight compositional differences along the interface relative to the average composition near the 
interface, with $\mathrm{Cr}$ slightly depleted and $\mathrm{Al}$ enriched at "peaks" and $\mathrm{Cr}$ slightly enriched at "valleys", Figure 4. However, these compositional changes were at most 1 at $\%$ and did not appear to include any phase precipitation. In both cases, $\mathrm{Y}$ ions were found to segregate to the alumina scale grain boundaries and the metal-oxide interface, as has been observed in many other alumina scales [9,12,17-23]. Cycling did not appear to affect segregation. Because of the short time and relatively low temperature, no Y-rich oxides had precipitated in the scale[22,23].

Based on the mass losses that occur after 150, 1h cycles (Figure 1), it is somewhat surprising that there was no indication of future failure after $100,1 \mathrm{~h}$ cycles. However, when examining the specimens after $100 \mathrm{~h}$ by SEM, localized areas were found that had already spalled after both isothermal and cyclic exposures, Figure 5a. Because both specimens spalled, this indicates that the interface roughening observed under thermal cycling (Figure 4) was not a primary factor in this localized scale spallation. However, it is possible that defects which lead to scale failure were confined to these localized spallation areas. If so, the unspalled oxide, which is what remains to be characterized, would not contain any incipient defects.

Isothermal and cyclic specimens were also examined after $200 \mathrm{~h}$ at $1100^{\circ} \mathrm{C}$. However, at this stage there was significant spallation on both specimens making TEM preparation difficult. One interesting observation on the cycled specimen was the presence of a few smooth regions on the metal substrate exposed by scale spallation, Figure $5 \mathrm{~b}$, that appeared to correspond to interfacial voids[24,25,26]. While such voids develop during oxidation of undoped $\mathrm{FeCrAl}$ $[10,11]$ or $\mathrm{NiAl}[18,24,25]$, they generally have not been observed on NiCrAls $[1,27]$. However, the number of voids was far fewer than normally observed on undoped $\mathrm{NiAl}$ [24].

While in principle the comparison of isothermally and cyclically formed oxides may be a good experimental approach, in this case, it did not prove useful in determining a mechanism for scale spallation on NiCrAlY. The absence of defects in either scale may indicate either that damage accumulation does not occur in scales or, as mentioned above, that damage does not aggregate uniformly in the scale but is highly localized. However, it could also indicate that the 
minimum flaw size that will initiate a crack leading to scale failure is very small, such that, when any defect nucleates, a crack propagates and spallation results at that location. In any of these cases, characterization of the remaining intact scale would not reveal incipient defects.

Several other NiCrAlY compositions with differing $\mathrm{Cr}$ and $\mathrm{Al}$ contents were also considered, Figure 1. However, because their resistance to scale spallation was not significantly better, microstructure comparisons instead were made with alumina scales formed on more spallation-resistant alloys.

\section{Monocrystal superalloy: René N5}

Compared to NiCrAlY, the cyclic oxidation performance of uncoated General Electric alloy René N5 (Ni-14Al-8Cr-7Co-2Ta-2W-1Re-1Mo-0.05Hf-0.05Y-7ppma S) is fairly good at $1100^{\circ} \mathrm{C}$, Figure 1 . No severe scale spallation was observed until after $1000 \mathrm{~h} \mathrm{[28]}$. The somewhat erratic mass change (Figure 1) is likely due to the spallation of the outer, Ni-rich transient layer which forms due to its lower $\mathrm{Cr}$ and $\mathrm{Al}$ contents [28]. After a 100h isothermal exposure at $1100^{\circ} \mathrm{C}$, this layer was $\approx 500 \mathrm{~nm}$ thick and contained $\mathrm{Ni}, \mathrm{Co}, \mathrm{Cr}$ and $\mathrm{Al}$, Figure 6 . At the transient oxide-alumina interface, numerous Ta-rich oxide particles were observed, as has been noted previously [9,29]. The underlying alumina layer showed no defects and was similar to that formed on NiCrAlY except that the column width $(\approx 0.3 \mu \mathrm{m}$ average) was somewhat smaller than that on NiCrAlY $(\approx 0.4 \mu \mathrm{m}$ average $)$. Both Hf and Ta ions, but not Y, were found segregated to the alumina scale grain boundaries and the metal-scale interface. Due to the low Y content of the alloy $(\approx 50 \mathrm{ppm})$, Y segregation may be difficult to detect in this case. Previous work on scales grown on René N5 at $1200^{\circ} \mathrm{C}$, did detect Y ion segregation [9].

The comparable $100 \mathrm{~h}$ cyclic specimen was not evaluated. However, because of its superior oxidation performance (Figure 1), it was not likely to show significant damage after only a 100 cycle exposure.

The fact that the very strong René N5 substrate performs better than the weak NiCrAlY substrate (Figure 1) does not fit a proposed spallation model based on substrate creep response 
[30]. Both alloys contain similar amounts of sulfur (NiCrAlY, 8ppma vs. René N5, 7ppma), therefore, any detrimental effect of sulfur cannot explain the difference in their performance. One possible factor which may contribute to the improved performance of René N5 relative to $\mathrm{NiCrAlY}$ is the presence of both $\mathrm{Hf}$ and $\mathrm{Y}$. The low solubility of $\mathrm{Y}$ leads to the formation of $\mathrm{NiY}_{\mathrm{X}}$ compounds, which are subject to internal oxidation and associated local scale spallation [31]. Hence the combination of a low level of Y with some Hf (which is more soluble than Y) may be beneficial. Another possibility is that the Ni-20Cr-19Al-0.05Y alloy does not contain sufficient Y but that does not appear likely, based on studies of higher Y levels in cast NiCrAlY [1]. Higher Y contents simply generate more internal oxide, which initiates more scale spallation.

\section{$\underline{\mathrm{NiAl}+\mathrm{Hf}}$}

An additional comparison was made with the scale formed on Hf-doped NiAl (Ni-50Al0.05Hf, <4ppma S), which is the most spallation-resistant alumina-forming substrate studied at this laboratory. Whereas the goal is to improve the oxidation performance of NiCrAlY, the optimized composition of $\mathrm{NiAl}+0.05 \% \mathrm{Hf}$ generally is modified in order to examine how various additives degrade its oxidation performance.

The alumina scale on NiAl+Hf is somewhat different than that formed on NiCrAlY. Due to the addition of $\mathrm{Hf}$, the steady-state isothermal scale growth rate at $1100^{\circ} \mathrm{C}$ is reduced to $1.1 \times 10^{-13} \mathrm{~g}^{2} \mathrm{~cm}^{4} / \mathrm{s}$ compared to $12-15 \times 10^{-13} \mathrm{~g}^{2} \mathrm{~cm}^{4} / \mathrm{s}$ for NiCrAlY. This is reflected in lower cyclic weight changes, Figure 1, and a thinner scale, Figure 7a. With the thinner oxide, the columnar structure is less evident, with the scale only one grain thick and the grains being similar in width and height. One interesting feature is that, although the entire scale is $\alpha-\mathrm{Al}_{2} \mathrm{O}_{3}$, the outer layer contains numerous voids, while the inner scale is virtually void free, Figure $7 \mathrm{~b}$. This voidage appears to mark the boundary between oxide which has transformed from cubic alumina (with the associated volume reduction creating the voids [32]) and oxide which grew as $\alpha$ phase. Based on a measured decrease in the scale growth rate, this transformation is complete by approximately $10 \mathrm{~h}$ at $1100^{\circ} \mathrm{C}$ and qualitatively corresponds to the observed thickness ratio of the 
void-containing layer to the total scale thickness.

Another interesting feature observed in the scale was a metal protrusion with an extremely thin overlying alumina layer, Figure 8a. An oxide grain above the protrusion appears to be misoriented such that there is no perpendicular grain boundary above the metal that would allow oxygen boundary transport and supply the reactant to form alumina. Rather than a deformation of the substrate, the protrusion appeared to form due to a local disruption in the normal diffusion through the scale. Metal protrusions have been observed in other alumina-forming systems $[33,34]$. With the overlying oxide being approximately the thickness of the transformed (voidcontaining) oxide, the misoriented grain may remain from initial, random nucleation of $\alpha-\mathrm{Al}_{2} \mathrm{O}_{3}$ grains at the metal-scale interface $[35,36]$.

Throughout the cross-section, Hf ions are found to segregate to the oxide grain boundaries and the metal-scale interface. An example is given in Figure $8 \mathrm{~b}$.

Despite all of the interesting observations in the cyclically-formed scale on Hf-doped $\mathrm{NiAl}$, there is no clear reason from a scale microstructure standpoint for the improved oxidation performance of Hf-doped NiAl compared to NiCrAlY. As observed in the scale on NiCrAlY, fine voids near the gas interface had no negative effect and no other defects were observed in the scale.

\section{$\underline{\mathrm{NiAl}+2 \mathrm{Cr}+\mathrm{Hf}}$}

One limitation of Hf-doped $\mathrm{NiAl}$ is that, due to the absence of $\mathrm{Cr}$ [37], it has poor hot corrosion resistance. Additions of $\mathrm{Cr}$ have been made to $\mathrm{NiAl}$ in an attempt to improve its hot corrosion resistance [6,8]. However, as shown in Figure 1, even 2\% Cr (Ni-49.6Al-2Cr-0.05Hf, 4ppm S) had a decidedly negative effect by accelerating the scale formation rate relative to $\mathrm{NiAl+Hf}$. At higher temperatures $\left(1200^{\circ} \mathrm{C}\right)$, this addition of $\mathrm{Cr}$ also eventually results in increased scale spallation compared to $\mathrm{NiAl}+\mathrm{Hf}[8]$ and negative effects have been noted previously [38]. Characterization of the scale formed on Hf-doped NiAl-2Cr showed that after $2 \mathrm{~h}$ at $1200^{\circ} \mathrm{C}$, small $\mathrm{Cr}$ precipitates began to form at the metal-scale interface, Figure 9 . These precipitates presumably formed due to the rejection of $\mathrm{Cr}$ from the growing scale and the low 
solubility of $\mathrm{Cr}$ in the $\beta$ matrix. It is suggested that these interfacial $\alpha$ precipitates will grow with increased exposure time and ultimately lead to spallation of the alumina scale, either due to their different coefficient of thermal expansion (10x $10^{-6}$ compared to $15 \times 10^{-6} \mathrm{~K}^{-1}$ for $\left.\beta[5,39]\right)$ or by reduced adhesion to the overlying alumina scale. However, it is not clear at this time why the addition of $\mathrm{Cr}$ accelerates the cyclic mass gain at $1100^{\circ} \mathrm{C}$, Figure 1 . Similar small $\alpha$ precipitates have been observed in simple and Pt-modified aluminide coatings [40,41].

While $\alpha$-Cr precipitation appears to be a probable scale failure mechanism for Hf-doped NiAl-Cr, it does not appear likely for NiCrAlY. Significant $\mathrm{Cr}$ solubility in the $\gamma$ phase of NiCrAlY should preclude $\alpha$ precipitation and initial characterization did not detect the presence of $\alpha$ precipitates at the metal-scale interface in NiCrAlY.

\section{Summary}

The scale on $100 \mathrm{~h}, 1100^{\circ} \mathrm{C}$ isothermally and cyclically-exposed $\mathrm{Ni}-20 \mathrm{Cr}-19 \mathrm{Al}-0.05 \mathrm{Y}$ specimens was examined in order to look for incipient damage in the alumina scale and provide a microstructural explanation for its poor performance in cyclic testing. However, only minimal differences were noted between the two microstructures with no evidence of increased defect formation in the thermally cycled scale. Analyses of alumina scales formed on René N5 and $\beta$ $\mathrm{NiAl}+\mathrm{Hf}$ also showed no significant damage in the alumina scale. When $\mathrm{Cr}$ is added to $\mathrm{NiAl}+\mathrm{Hf}$, oxidation performance is degraded and $\alpha$-Cr precipitates are observed at the metal-scale interface. These precipitates may lead to scale spallation for NiAl. However, in the case of NiCrAlY, they would not be expected to form and were not observed.

\section{Acknowledgments}

The authors are thankful to G. Garner and L. D. Chitwood for assistance with the oxidation work, T. Geer for metallography and K. S. Trent and D. Coffey for TEM-FIB specimen 
preparation and M. Lance, M. brady and J. DiStefano for comments on the manuscript. The research was sponsored by the Fossil Energy Advanced Research and Technology Development (AR\&TD) Materials Program, and the Advanced Turbine Systems Program, U. S. Department of Energy, under contract DE-AC05-96OR22464 with Lockheed Martin Energy Research Corp.

\section{References}

1. Pint, B. A. and Wright, I. G. Cyclic oxidation behavior of cast $\mathrm{NiCrAl}$ alloys, in P. Y. Hou, M. J. McNallan, R. Oltra, E. J. Opila and D. A. Shores eds., High Temperature Corrosion and Materials Chemistry, Electrochem. Soc. Proc. v.98-9, 263-74 (1998).

2. Miller, R. A. Life modeling of thermal barrier coatings for aircraft gas turbine engines, J. Eng. Gas Turb. \& Power 111, 301-5 (1989).

3. Lowell, C. E., Garlick, R. G. and Henry, B. Thermal expansion in the Ni-Cr-Al and Co$\mathrm{Cr}$-Al systems to $1200^{\circ} \mathrm{C}$ determined by high-temperature x-ray diffraction, Met. Trans. 7A, 65560 (1976).

4. Smialek, J. L., Doychak J. and Gaydosh, D. J. Oxidation behavior of FeAl + Hf, Zr, B, Oxid. Met. 34, 259-75 (1990).

5. Haynes, J. A., Pint, B. A., Porter, W. D. and Wright, I. G Relationships between thermal expansion and oxidation behavior of various superalloys and high-temperature coating materials, to be submitted to Scripta Mat. (1999).

6. Ellis, D. L. Hot corrosion of the B2 nickel aluminides, NASA Report, CR191082, NASA, Cleveland, OH (1993).

7. Leyens, C., Wright, I. G. and Pint, B. A. Hot corrosion of Ni-base alloys in biomass derived fuel simulated atmosphere, in J. M. Hampikian and N. B. Dahotre eds., Elevated Temperature Coatings: Science and Technology III, TMS Symp. Proc., Warrendale, PA, p.79-90. 8. Leyens, C., Pint, B. A. and Wright, I. G. Effect of composition on the hot corrosion resistance of $\mathrm{NiAl}$ and $(\mathrm{Ni}, \mathrm{Pt}) \mathrm{Al}$, for submission to NACE Corrosion 2000, Orlando, Fl, April, 2000.

9. $\quad$ Pint, B. A., Wright, I. G., Lee, W. Y., Zhang, Y., Prüßner, K. and Alexander, K. B. Substrate and bond coat compositions: factors affecting alumina scale adhesion, Mater. Sci. Eng. A245, 201-11 (1998).

10. More, K. L., et al. These proceedings.

11. Golightly, F. A., Stott, F. H. and Wood G. C. The relationship between oxide grain morphology and growth mechanisms for Fe-Cr-Al and Fe-Cr-Al-Y alloys, J. Electrochem. Soc. 
126, 1035-42 (1979).

12. Pint, B. A., Garratt-Reed, A. J. and Hobbs, L. W. The reactive element effect in commercial ODS FeCrAl alloys, Mater. High Temp. 13, 3-16 (1995).

13. Pint, B. A. The oxidation behavior of oxide-dispersed $\beta$-NiAl: I. Short-term cyclic data and scale morphology, Oxid. Met. 49, 531-60 (1998).

14. Haynes, J. A., Ferber, M. K. and Rigney, E. D. Characterization of alumina scales formed during isothermal and cyclic oxidation of plasma-sprayed TBC systems at $1150^{\circ} \mathrm{C}$, Oxid. Met. 52, 31-76 (1999).

15. Doychak, J. and Rühle, M. TEM studies of oxidized $\mathrm{NiAl}$ and $\mathrm{Ni}_{3} \mathrm{Al}$ cross sections, Oxid. Met. 31, 431-52 (1989).

16. Pint, B. A., Garratt-Reed, A. J. and Hobbs, L. W. Analytical electron microscopy study of the breakdown of $\alpha-\mathrm{Al}_{2} \mathrm{O}_{3}$ scales formed on oxide dispersion strengthened alloys, submitted to Met. Trans. A, (1999).

17. Tawancy, H. M. and Sridhar, N. High-temperature oxidation behavior of a Ni-Cr-Al-Fe-Y alloy, Oxid. Met. 37, 143-66 (1992).

18. Pint, B. A. and Hobbs, L. W. Limitations on the use of ion implantation for the study of the reactive element effect in $\beta$-NiAl, J. Electrochem. Soc. 141, 2443-53 (1994).

19. Schumann, E., Yang, J. C., Graham, M. J. and Rühle, M. Segregation studies of oxidized Y and Zr doped NiAl, Mater. Corr. 46 218-22 (1995).

20. Mennicke, C., Schumann, E., Ulrich, C. and Rühle, M. The effect of yttrium and sulfur on the oxidation of FeCrAl, Mat. Sci. Forum 251-4 389-96 (1997).

21. Prüßner, K., Pint, B. A., Alexander, K. B. and Tortorelli, P. F. Failure analysis of alumina scales on NiCrAl-alloys, Electrochem. Soc. Meeting Abstracts 98-1, 799 (1998).

22. Pint, B. A., Garratt-Reed, A. J. and Hobbs, L. W. Possible role of the oxygen potential gradient in enhancing diffusion of foreign ions on $\alpha-\mathrm{Al}_{2} \mathrm{O}_{3}$ grain boundaries, J. Amer. Ceram. Soc. 81, 305-14 (1998).

23. Pint, B. A. Experimental observations in support of the dynamic segregation theory to explain the reactive element effect, Oxid. Met. 45, 1-37 (1996).

24. Smialek, J. L. Oxide morphology and spalling model for NiAl, Met. Trans. 9A, 309-20 (1978).

25. Pint, B. A. On the formation of interfacial and internal voids in $\alpha-\mathrm{Al}_{2} \mathrm{O}_{3}$ scales, Oxid. Met. 48, 303-28 (1997).

26. Smeggil, J. G. Some comments on the role of yttrium in protective oxide scale adherence, Mat. Sci. and Eng. 87, 261-5 (1987).

27. Smialek, J. L. Sulfur impurities and the microstructure of alumina scales, Microscopy of Oxidation-3, S. B. Newcomb and J. A. Little eds, p.127-39, Institute of Materials, London (1997). 
28. Pint, B. A., Tortorelli, P. F. and Wright I. G. Effect of cycle frequency on high temperature oxidation behavior of alumina- and chromia-forming alloys, EFC Cyclic Oxidation Workshop, February 1999, in press.

29. Wright, I. G., Pint, B. A., Lee, W. Y., Alexander, K. B. and Prüßner, K. Some effects of metallic substrate composition on degradation of thermal barrier coatings, in J. Nicholls, ed., High Temperature Surface Engineering, Institute of Materials, London, UK, in press.

30. Evans, H. E., Nicholls, J. R. and Saunders, S. R. J. The influence of diffusion-related mechanisms in limiting oxide-scale failure, Solid State Phenom. 41, 137-56 (1995).

31. Kuenzly, J. D. and Douglass, D. L. The oxidation mechanism of $\mathrm{Ni}_{3} \mathrm{Al}$ containing yttrium, Oxid. Met. 8, 139-178 (1974).

32. Doychak, J. Oxidation behavior of high temperature intermetallics, in Intermetallic Compounds, Vol.1: Principles, J. H. Westbrook and R. L. Fleischer eds., John Wiley \& Sons, New York, NY, p.977-1016 (1994).

33. Felten, E. J. and Pettit, F. S. Development, growth, and adhesion of $\mathrm{Al}_{2} \mathrm{O}_{3}$ on PlatinumAluminum Alloys, Oxid. Met. 10, 189-223 (1976).

34. Hindam, H. M. and Smeltzer, W. W. Growth and microstructure of $\alpha-\mathrm{Al}_{2} \mathrm{O}_{3}$ on $\beta-\mathrm{NiAl}, \mathrm{J}$. Electrochem. Soc. 127, 1630-5 (1980).

35. Schumann, E. The effect of Y-ion implantation on the oxidation of $\beta$-NiAl, Oxid. Met. 43, 157-72 (1995).

36. Yang, J. C., Schumann, E., Levin, I. and Rühle, M. Transient oxidation of NiAl, Acta Mater. 46, 2195-201 (1998).

37. Rapp, R. A. Chemistry and electrochemistry of hot corrosion of metals, Mater. Sci. Eng. 87, 319-27 (1987).

38. Smeggil, J. Surf. Coat. Tech. 46, 143 (1991).

39. Fritscher, K., Leyens, C. and Peters, M. Development of a low-expansion bond coating for Ni-base superalloys, Mater. Sci. Eng. A190, 253-8 (1995).

40. Gale, W. F. and King, J. E. Precipitation of chromium containing phases in aluminide coated nickel-base superalloy single crystals, J. Mater. Sci. 28, 4347-54 (1993).

41. K. L. More, Y. Zhang and A. Haynes, unpublished research, Oak Ridge National Laboratory, 1998. 
Figure Captions

Figure 1. Mass changes during $1 \mathrm{~h}$ cycles at $1100^{\circ} \mathrm{C}$ in dry flowing $\mathrm{O}_{2}$ for various $\mathrm{NiCrAl}$ and $\mathrm{NiAl}$ alloys.

Figure 2. Scale on Ni-20Cr-19Al-0.05Y after 100 , $1 \mathrm{~h}$ cycles at $1100^{\circ} \mathrm{C}$, (a) SEM bright field plan view of surface oxide, (b) light microscopy of metallographic cross-section showing two phases and internal oxidation of Y (large arrow) and (c) SEM bright field cross-section of alumina scale.

Figure 3. TEM bright field images of alumina scale formed on $\mathrm{Ni}-20 \mathrm{Cr}-19 \mathrm{Al}-0.05 \mathrm{Y}$ at $1100^{\circ} \mathrm{C}$ after (a) 100, 1h cycles and (b) 100h isothermal. Both have a columnar structure with voids (arrows) only near the gas interface and no cracks.

Figure 4. TEM bright field images of alumina scale formed on $\mathrm{Ni}-20 \mathrm{Cr}-19 \mathrm{Al}-0.05 \mathrm{Y}$ at $1100^{\circ} \mathrm{C}$ after (a) 100, $1 \mathrm{~h}$ cycles and (b) $100 \mathrm{~h}$ isothermal. The isothermal interface is more faceted and geometric than the cycled interface.

Figure 5. SEM secondary electron plan-view images of Ni-20Cr-19Al-0.05Y oxidized at $1100^{\circ} \mathrm{C}$ : (a) spalled regions after $100 \mathrm{~h}$ isothermal and (b) exposed metal in spalled region after 200, $1 \mathrm{~h}$ cycles. In both cases spallation is to bare metal, in (b) the smooth regions appear to correspond to an interfacial void.

Figure 6. TEM bright field image of the scale formed on René $\mathrm{N} 5$ after $100 \mathrm{~h}$ at $1100^{\circ} \mathrm{C}$. A thicker Ni-rich transient oxide forms on this alloy due to its low $\mathrm{Cr}$ and $\mathrm{Al}$ content and Ta-rich precipitates (arrows) are observed at the alumina-transient oxide interface.

Figure 7. TEM bright field images of the alumina scale formed on Hf-doped NiAl after 100, 1h cycles at $1100^{\circ} \mathrm{C}$. At higher magnification (b), there is a clear division between the outer scale containing voids and the lower, denser oxide.

Figure 8. (a) TEM bright field image of the scale formed on NiAl+Hf after 100, $1 \mathrm{~h}$ cycles at $1100^{\circ} \mathrm{C}$ (b) Hf EDS x-ray map from box in (a) shows segregation of Hf ions at oxide grain boundary and at metal-oxide interface. Center of (a) shows a metal protrusion into the scale with a misoriented alumina grain above (arrow).

Figure 9. (a) TEM bright field image of the alumina scale formed on Ni-49Al-2Cr+Hf after $2 \mathrm{~h}$ at $1200^{\circ} \mathrm{C}$; (b) $\mathrm{Cr}$ EDS X-ray map at the interface reveals $\mathrm{Cr}$-rich precipitates (arrows) in the metal adjacent to the metal-scale interface. 


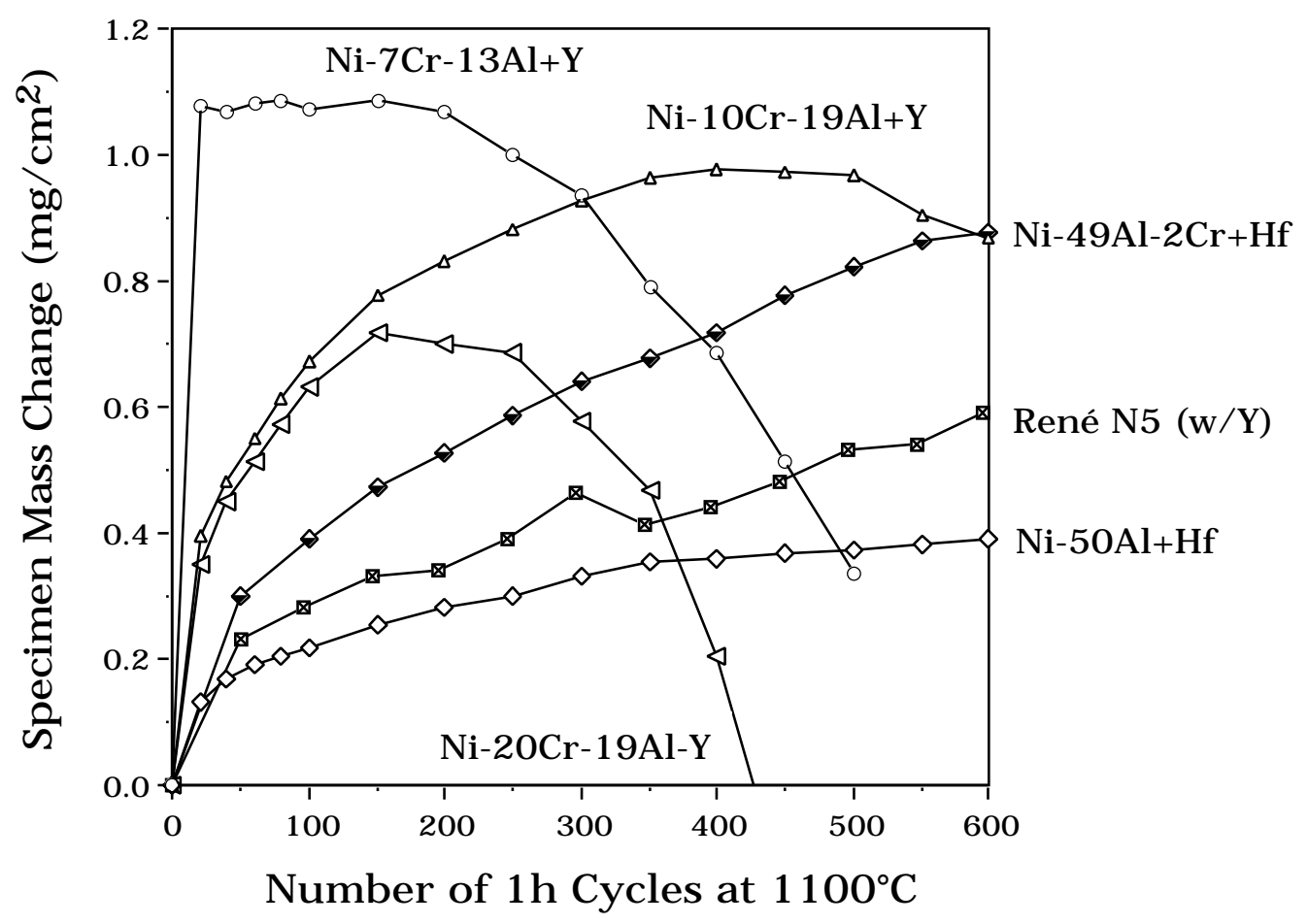

Figure 1. Mass changes during $1 \mathrm{~h}$ cycles at $1100^{\circ} \mathrm{C}$ in dry flowing $\mathrm{O}_{2}$ for various $\mathrm{NiCrAl}$ and $\mathrm{NiAl}$ alloys.
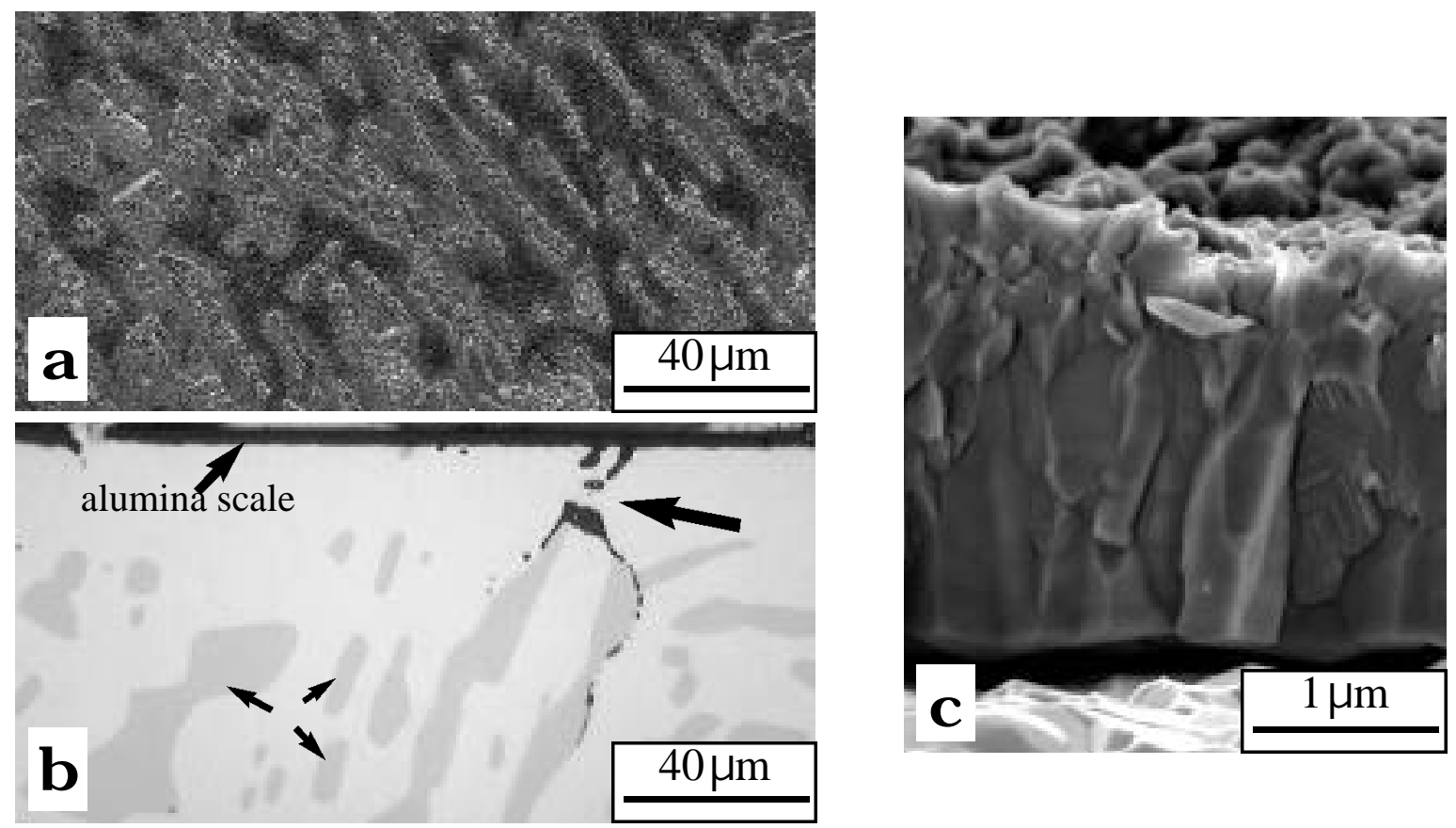

Figure 2. Scale on Ni-20Cr-19Al-0.05Y after 100 , $1 \mathrm{~h}$ cycles at $1100^{\circ} \mathrm{C}$, (a) SEM bright field plan view of surface oxide, (b) light microscopy of metallographic cross-section showing two phases and internal oxidation of Y (large arrow) and (c) SEM bright field cross-section of alumina scale. 

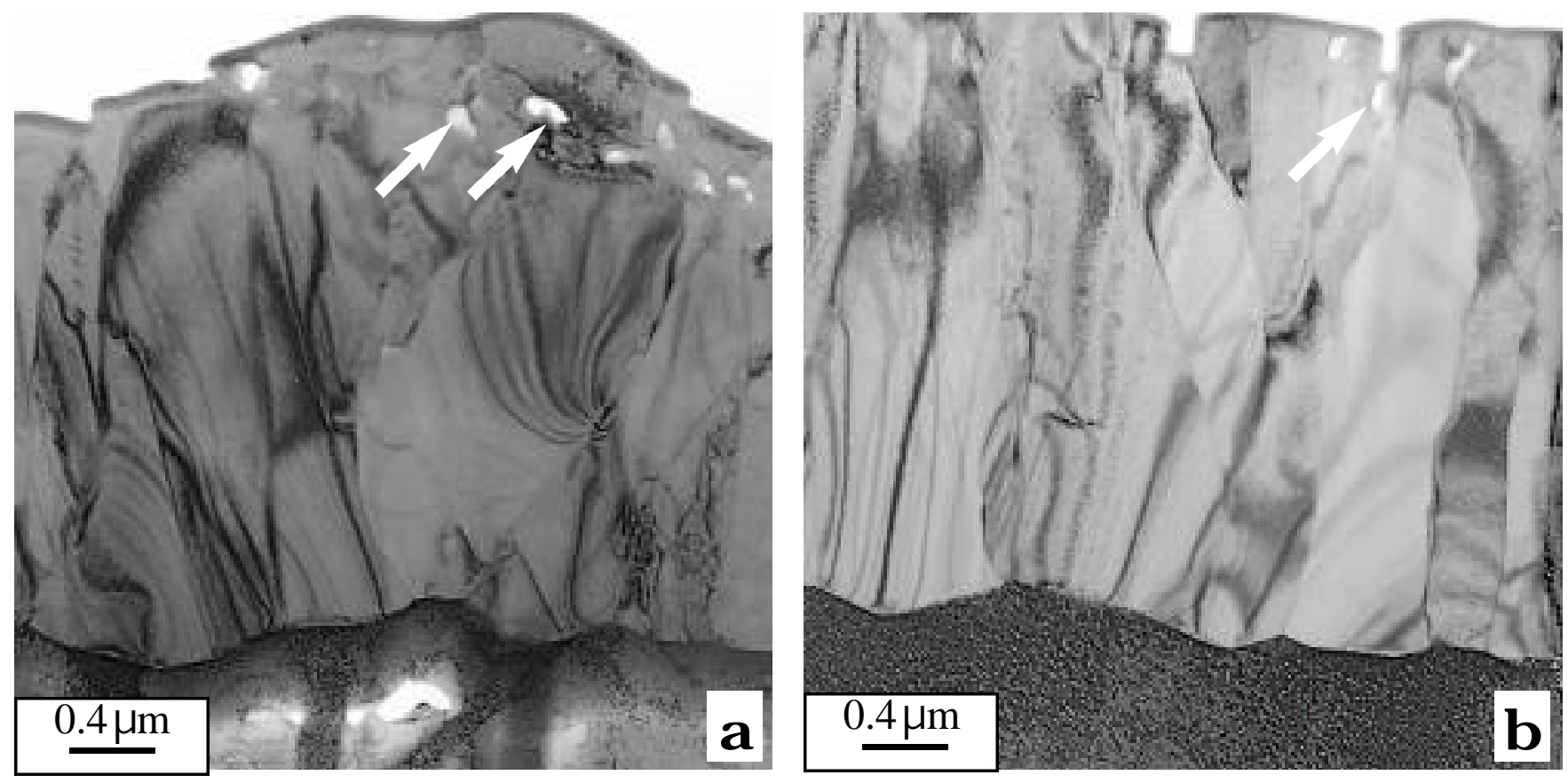

Figure 3. TEM bright field images of alumina scale formed on $\mathrm{Ni}-20 \mathrm{Cr}-19 \mathrm{Al}-0.05 \mathrm{Y}$ at $1100^{\circ} \mathrm{C}$ after (a) $100,1 \mathrm{~h}$ cycles and (b) 100h isothermal. Both have a columnar structure with voids (arrows) only near the gas interface and no cracks.
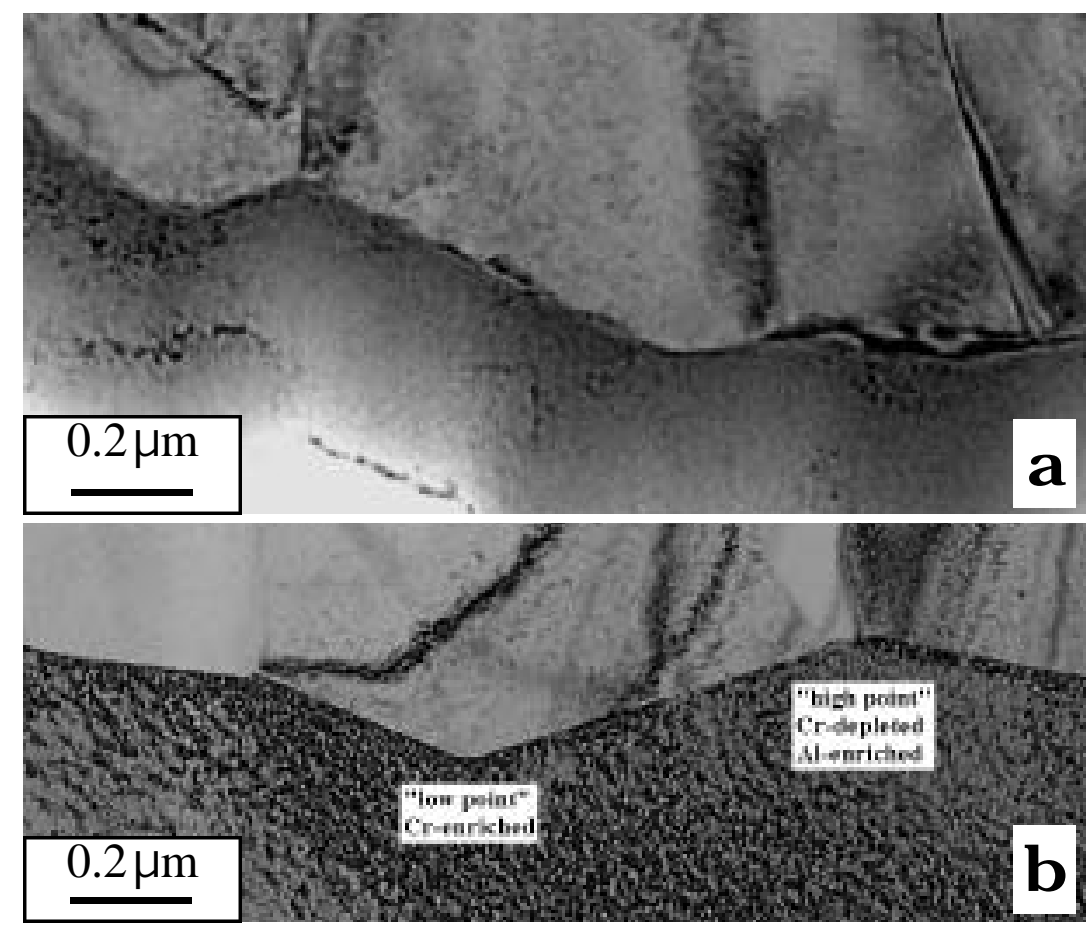

Figure 4. TEM bright field images of alumina scale formed on Ni-20Cr-19Al-0.05Y at $1100^{\circ} \mathrm{C}$ after (a) $100,1 \mathrm{~h}$ cycles and (b) $100 \mathrm{~h}$ isothermal. The isothermal interface is more faceted and geometric than the cycled interface 

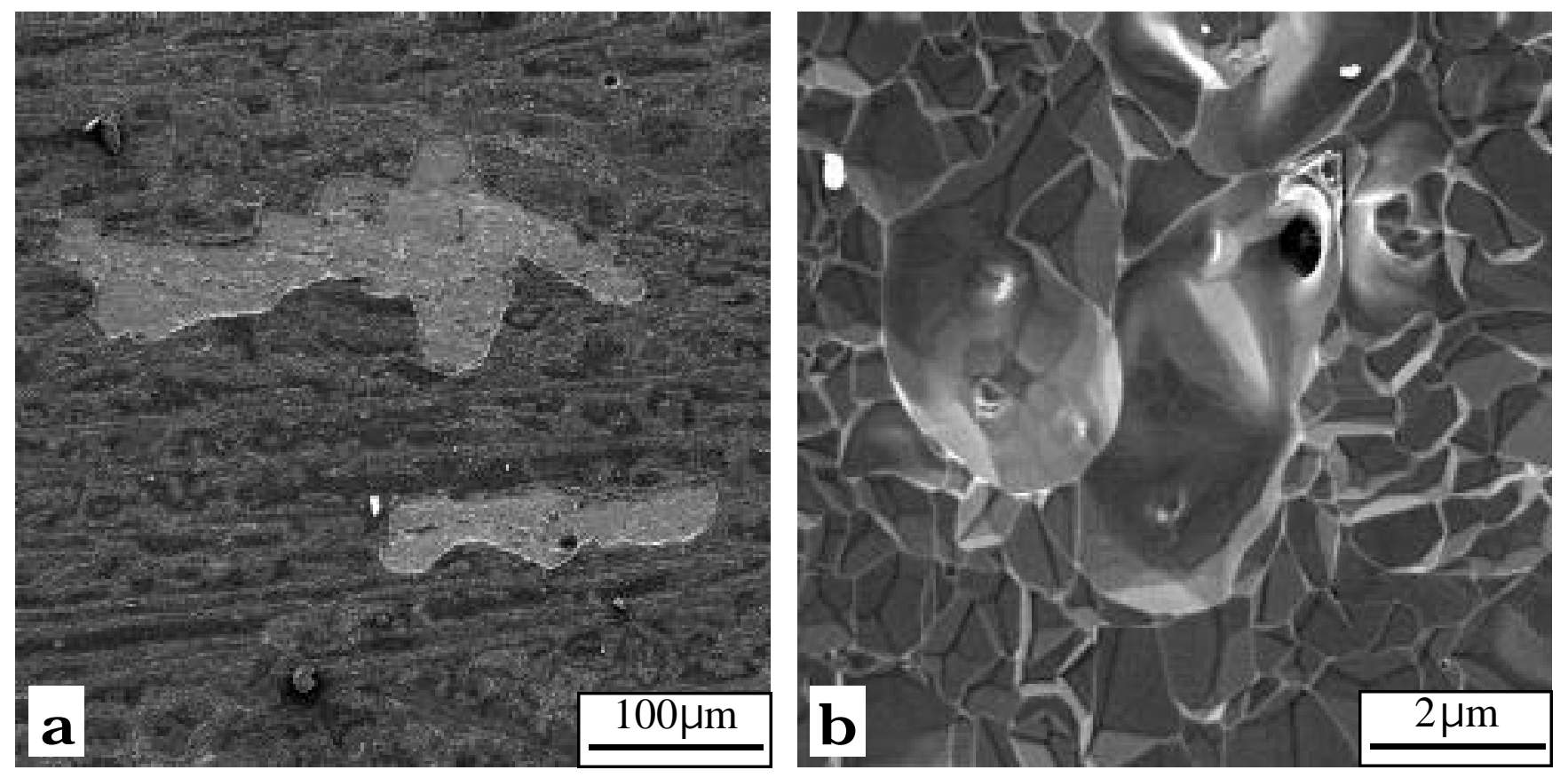

Figure 5. SEM secondary electron plan-view images of Ni-20Cr-19Al-0.05Y oxidized at $1100^{\circ} \mathrm{C}$ : (a) spalled regions after $100 \mathrm{~h}$ isothermal and (b) exposed metal in spalled region after $200,1 \mathrm{~h}$ cycles. In both cases spallation is to bare metal, in (b) the smooth regions appear to correspond to an interfacial void.

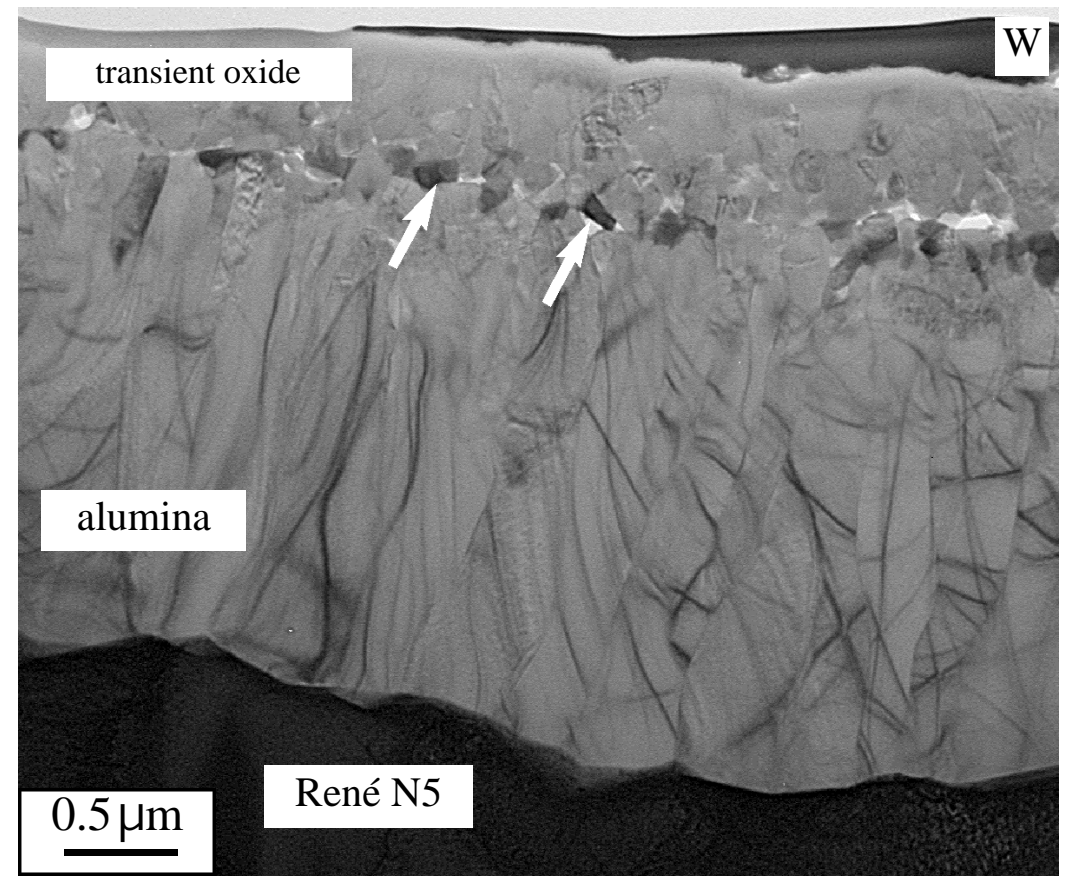

Figure 6. TEM bright field image of the scale formed on René N5 after $100 \mathrm{~h}$ at $1100^{\circ} \mathrm{C}$. A thicker Nirich transient oxide forms on this alloy due to its low $\mathrm{Cr}$ and $\mathrm{Al}$ content and Ta-rich precipitates (arrows) are observed at the alumina-transient oxide interface. 


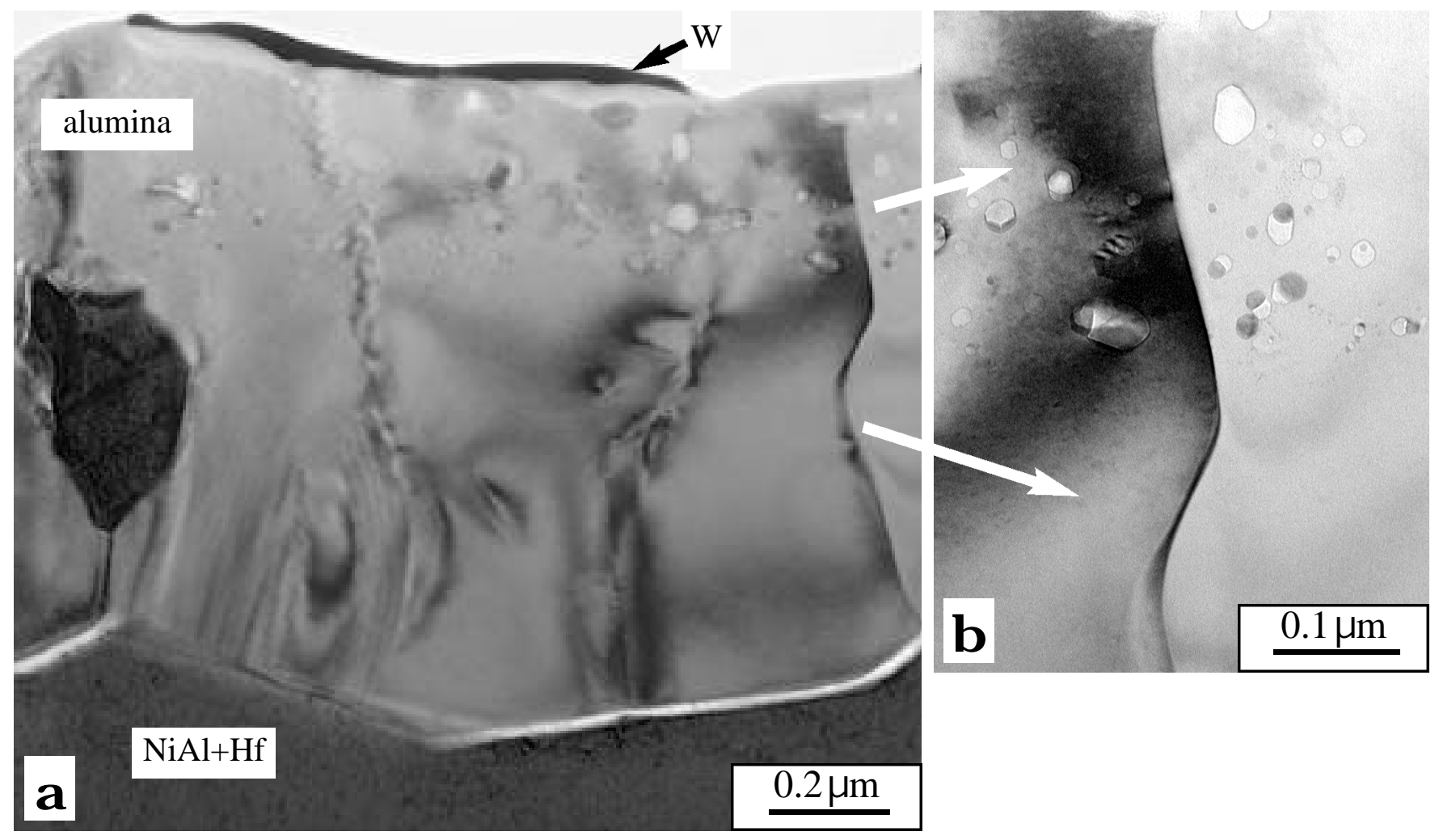

Figure 7. TEM bright field images of the alumina scale formed on Hf-doped NiAl after 100, $1 \mathrm{~h}$ cycles at $1100^{\circ} \mathrm{C}$. At higher magnification (b), there is a clear division between the outer scale containing voids and the lower, denser oxide.
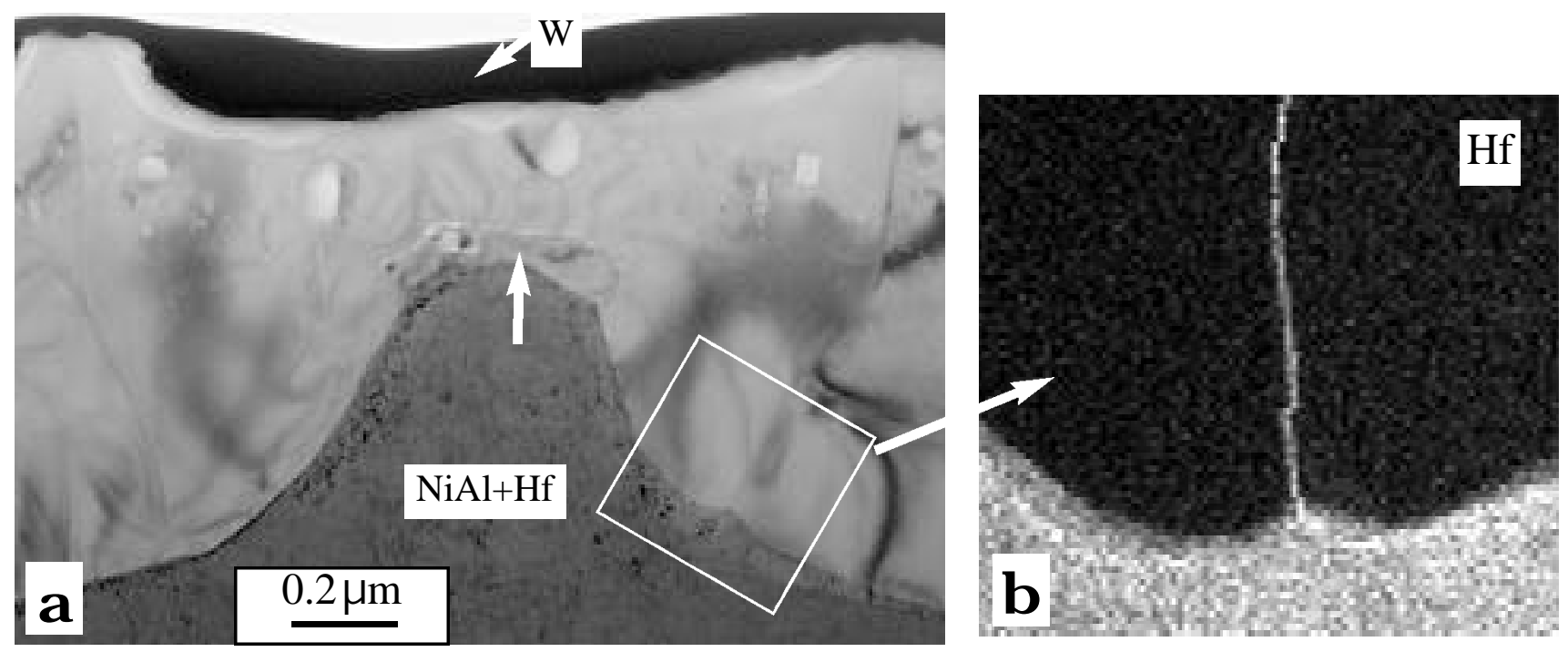

Figure 8. (a) TEM bright field image of the scale formed on NiAl+Hf after $100,1 \mathrm{~h}$ cycles at $1100^{\circ} \mathrm{C}$ (b) Hf EDS x-ray map from box in (a) shows segregation of Hf ions at oxide grain boundary and at metaloxide interface. Center of (a) shows a metal protrusion into the scale with a misoriented alumina grain above (arrow). 


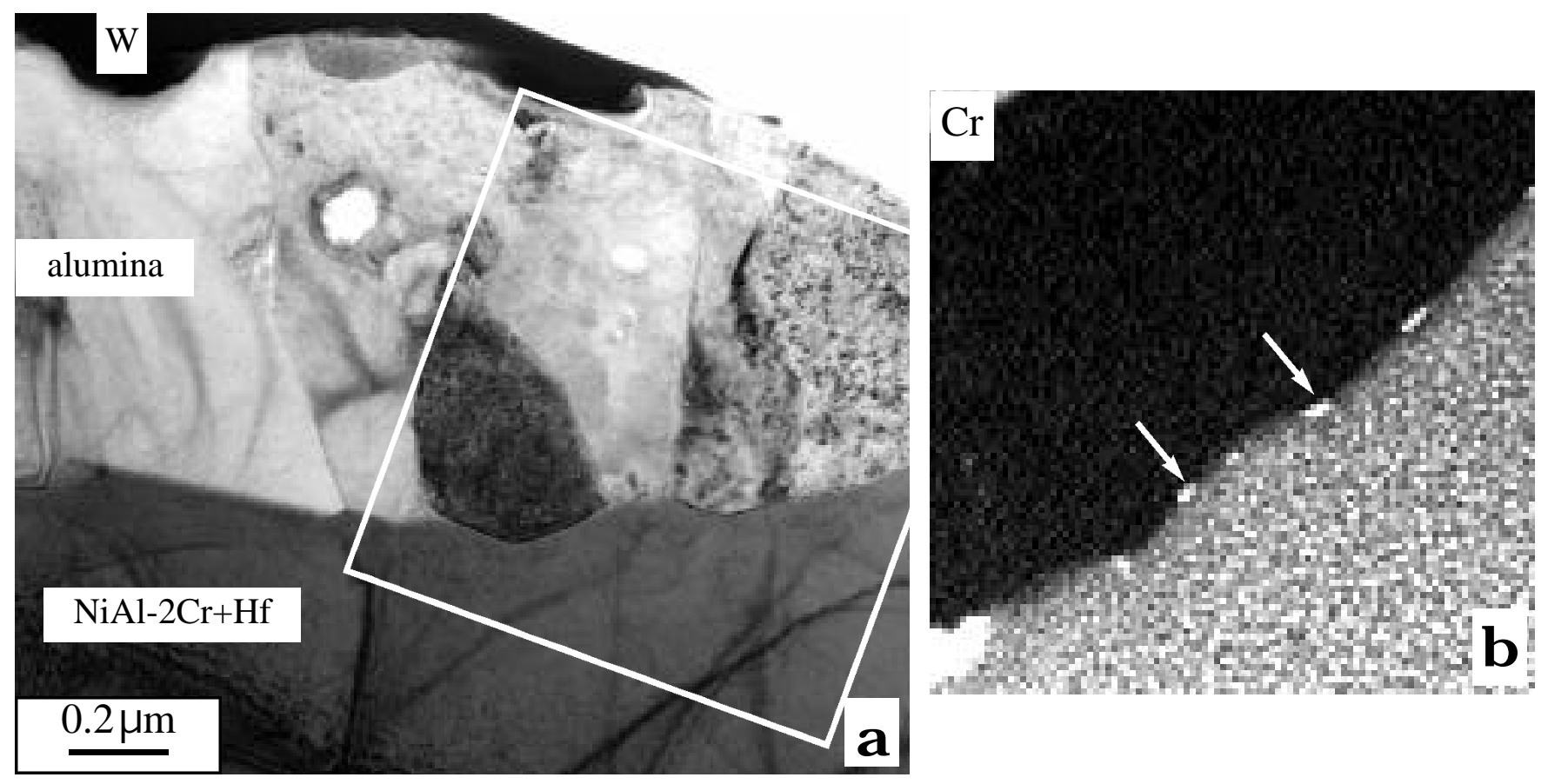

Figure 9. (a) TEM bright field image of the alumina scale formed on $\mathrm{Ni}-49 \mathrm{Al}-2 \mathrm{Cr}+\mathrm{Hf}$ after $2 \mathrm{~h}$ at $1200^{\circ} \mathrm{C}$; (b) $\mathrm{Cr}$ EDS X-ray map at the interface reveals Cr-rich precipitates (arrows) in the metal adjacent to the metal-scale interface. 